\title{
The Social Life of Gas Stations
}

\author{
Giulio Giovannoni \\ University of Florence, Italy \\ Department of Architecture \\ giulio.giovannoni@unifi.it
}

\begin{abstract}
Literature on gas stations is limited to a handful of approaches: the nostalgic/historical approach concerning the first vernacular manifestations of such roadside artefacts; the bleak approach, stressing the character of 'non-places' of these spaces; the obvious technological and functionalist approach; and a few other minor ones. Almost never gas stations are considered as public spaces. However gas stations, as well as other kerbside artefacts, abound of social life. This is particularly true in Italy, where thanks to the post-war tradition of Autogrill, gas stations are often much more than just a place to fill up a car. They provide coffee shops, restaurants, pastry shops, as well as newsstands, stores, food vendors, not to say more recently the inevitable Mac Drives. All activities that are accessible, with easy parking, and in many instances open $24 / 7$, in a country which shuts at $7.00 \mathrm{pm}$, or at best at $9.00 \mathrm{pm}$. Therefore, gas stations become the crossroads of many social interactions, especially - but not only - of youth subcultures. For these reasons gas stations deserve being studied for what they are, avoiding both nostalgic and bleak approaches. This paper presents the first results of an ongoing research on the social life of gas stations in central Italy. It is structured in five main sections. Section one synthesizes the main theoretical positions on gas stations, from the pessimistic ones equating gas stations to nonplaces, to the more optimistic framing gas stations within street and car cultures. Section two frames the relevance of gas stations within the wider transformation produced on cities by the advent of car. Section three provides an historical framework in order to explain today's social relevance of gas stations in Italy. Section four presents the research findings on the social life of such 'architectures in motion', confirming the importance of gas stations for public life. The final section of the paper draws policy implications of such findings claiming the necessity of explicitly designing gas stations as places for public life.
\end{abstract}

Keywords: public life; gas stations; suburban life; non-places; public spaces.

\section{To cite this article:}

Giovannoni, G. (2016). The Social Life of Gas Station. The Journal of Public Space, I (I), 75-94, DOI: 10.5204/jps.vlil.I2

This article has been peer-reviewed and accepted for publication in The Journal of Public Space. Please see the Editorial Policies under the 'About' section of the journal website for further information.

\section{(c) (i) \$)}

This work is licensed under a Creative Commons Attribution - Non Commercial 4.0 International License. https://creativecommons.org/licenses/by-nc/4.0/ 


\section{A hated-loved object}

Since their appearance gas stations have been loved and hated: loved by street culture enthusiasts, especially in their first manifestations; hated by those adverse to car culture and its impact on contemporary cities. In any case, the importance of gas stations in everyday life goes well beyond its mundane role. Several researchers consider infrastructure-related spaces as 'non-places'. The concept of 'non-place' was introduced by the French anthropologist Marc Augé (1995) to describe what he defines as the typical space of hypermodernity. According to Augé hypermodernity is an historical moment characterised by excesses: excess of time, being time "overloaded with events that encumber the present along with the recent past" (p. 29); and excess of space, growing the Earth smaller and allowing us "an instant, sometimes simultaneous vision of an event taking place on the other side of the planet" (p. 3I). Such overexposure makes us lose the sense of time and the sense of space. Being manifestations of a condition of separation from time and space, 'non-places' are condemned to the impossibility of being arenas of social life (p. III):
Since nonplaces are the space of supermodernity, supermodernity cannot aspire to the same ambitions as modernity. When individuals come together, they engender the social and organize places. But the space of supermodernity is inhabited by this contradiction: it deals only with individuals (customers, passengers, users, listeners), but they are identified (name, occupation, place of birth, address) only on entering or leaving. Since non-places are the space of supermodernity, this paradox has to be explained: it seems that the social game is being played elsewhere than in the forward posts of contemporaneity. It is in the manner of immense parentheses that non-places daily receive increasing numbers of individuals.

In Italy Augé's position is shared by Paolo Desideri (1995); Desideri describes an autogrill, the typically Italian motorway restaurant with annexed gas station, crowded with an heterogeneous metropolitan population arrived there to eat ready-made sandwiches. He misses the time when "at night, in towns, in main streets, in nice Italian piazzas, we met to add our own history to the collective one" (p. 13). According to Desideri, "the collective actions going on in a 'non-place' perpetually remains the summation of single individualities never arriving to express themselves as the integral of a shared public identity (p. 77). But nevertheless Desideri admits that keeping on with applying to this 'tinplate city' the spatial configuration categories of the historical city only produces "effects of complete desolation and of stronger bewilderment" and that it's necessary to open-mindedly design the spaces of a civitas which is essentially made of travellers and of consumers.

Obviously, the way gas stations and infrastructure-related spaces are perceived depends on the cultural context. Northern American scholars are generally more interested in street cultures and its manifestations; in particular, the tradition of cultural landscape studies attributes great dignity to all kind of spaces that have an impact on everyday life, even if with no real architectural value, including spaces related to the typical streetscape generated by car culture. The same spaces which are classified as 'non-places' by Marc Augé, become both socially and culturally interesting locales. For example, parking lots are defined by Kunstler (1994: 136) the "most common little dead 'non-places' of the postwar streetscape”; John Brinckerhoff Jackson (1997: 76, in Eran Ben-Joseph, 20I2) instead argues: 
I am tempted to dwell on the importance of the parking lot. I enjoy it as an austere but beautiful and exciting aspect of the landscape. I find it easy to compare it with such traditional vernacular spaces as the common: both are undifferentiated in form, empty, with no significant topographical features to determine use, both easily accessible and essential to our daily existence. But on another level, the parking lot symbolizes a closer, more immediate relationship between various elements in our society: consumer and producer, public and private, the street and the dwelling.

Furthermore, the way gas stations and infrastructure-related spaces are perceived has changed considerably in time. In post World War II, when the car was almost anywhere a symbol of liberty and wealth, gas stations had a positive meaning much more than they have today. However, already in the 1960s, bleak depictions of that spaces were emerging. A view of motorway restaurants as alienating and homogenizing places is conveyed for example by the 1963 movie Ro.Go.Pa.G. At that time in Italy the motorway restaurant, commonly named autogrill, was an incredibly powerful symbol of modernity and affluence (see $\S 3$ ). In the episode II pollo ruspante (The ground-raised chicken), directed by Ugo Gregoretti, the stop at the autogrill during a Sunday trip literally transforms visitors in battery chickens, oblivious of the liberty of their ground-raised ancestors, and only interested in mass consumption. While the leading actor buys useless goods and eats a standardized meal together with his family, Professor Pizzorno, a renowned Italian sociologist, holds a conference on consumption, where he invites "to always study new advertising campaigns in order to stimulate new desires, new needs, so to create a sort of systematic dissatisfaction in consumers". The episode ends with a scene in which the actors, sitting at table in the motorway restaurant, are transformed in battery chickens.

Although many consider infrastructure related artifacts only as a manifestation of the worst aspects of modernity, these artifacts can provide in many places opportunities of urban embellishment. In the words of Oriol Bohigas (1986, quoted in Ingersoll, 2006):

It is necessary to interrupt the old and counterproductive dichotomy between urbanism and the politics of public works, which has given a schizophrenic tone to the development of our cities. While the urbanists analyzed and planned, looking for a new method to work on the city, the technicians of public works continued to work in the healthy tradition of constructing the city realistically, but without an integrated vision of its areas ... or devoting themselves unilaterally to traffic engineering. It is time to approach urbanism with the tools of public works; build an urbanism that is capable of uniting and harmonizing the projects of urbanization. Designing and realizing plazas, streets, boulevards, ramblas, intersections, pedestrian paths, street furniture, street signs, monuments.

Also in the last decades there was a growing awareness about the possible role of transportation networks as structuring elements of social spaces. Infrastructural interventions realized in Barcelona under the direction of Oriol Bohigas between 1980 and 1992, offered the opportunity of rethinking in an integrated fashion the system of public spaces, globally redesigning the city aspect and style. However, apart from the aforementioned cases, the so-called 'non-places' are rarely designed with explicit attention to the public life which they can possibly host. This is true also in the case of gas stations, whose literature deals mainly with three approaches: a historic/nostalgic approach concerning the first vernacular incarnation of such roadside artifacts; the aforementioned bleak approach stressing their character of 'non-places'; and the obvious 
technological/functionalist approach of engineering character. Gas stations are almost never considered as public spaces, but gas stations, as other roadside artifacts, abound in social life. This is particularly true in Italy, where thanks to the post-war tradition of Autogrill and Ristoragip, gas stations are much more than places to fill up vehicles.

\section{Gas Stations, the Car and the City}

The urban and social importance of gas stations should be framed contextually to the transformations produced by the car in cities and in everyday life. In preindustrial cities, but more precisely before the advent of the car, thoroughfares coincided with the mostly crowded and vibrant public spaces. Before the car era the subsequent equation was true:

$$
\text { [COMMERCIAL SPACES } \equiv \text { THOROUGHFARES } \equiv \text { PUBLIC SPACES] }
$$

Commercial spaces, thoroughfares, and public spaces tended to coincide. The advent of the car made all of that impossible. The car was too big and fast to fit in the public spaces of cities which had not been explicitly designed to hold it. In the beginning the coexistence was forced and there was no way out of congestion. That was the time the urban crisis exploded. This happened earlier in the biggest northern American cites, later on in European and Italian cities.

Afterwards urban managers and politicians started coping with the new situation. On the one hand some great urban utopias envisioning a global revolution in cities were developed; on the other hand practical policies were developed to ease the situation of existing congestion in cities. Regarding the car/city relationship, these policies are in a range between two extremes. At one extreme we have policies aimed at adapting the city to the car; various contemporary versions of Haussmann's approach whose most famous cases probably are the Boston Central Artery and Robert Moses' interventions in New York, but which with various degrees have been adopted in almost every American and European city. In this case the aforementioned relationship becomes:

\section{[COMMERCIAL SPACES $\equiv$ PUBLIC SPACES] - THOROUGHFARES}

The single hyphen linking both commercial spaces and public spaces to thoroughfares means the relationship at the same time of spatial proximity and of physical separation. Public spaces and commercial spaces, instead, still tend to coincide as before. At the opposite extreme the car was completely banned from cities separating residential zones and public spaces from traffic. Being accessibility vital to commerce, the separation of traffic from public spaces also implied the disconnection of the latter from businesses, being this in fact non separable from the main thoroughfares. This solution was adopted in many modernist plans, which devised residential neighbourhoods equipped with pedestrian public spaces and commercial areas astride the same neighbourhoods and the main thoroughfares. The aforementioned equation was then changed into the subsequent:

$$
\text { PUBLIC SPACES - COMMERCIAL SPACES - THOROUGHFARES }
$$

In this case commercial spaces are in a relationship both of spatial proximity and of physical separation (single hyphen), with thoroughfares and with public spaces at the same time. Public spaces instead are completely separated from thoroughfares. 
Between these two extremes, in which the governance dimension is in a sense predominant, is a complex reality produced by the natural tendency of the market and by the almost unrestricted freedom of movement made possible by the car. This tendency had been largely foreshadowed by Frank Lloyd Wright, who envisaged the sprawl of residential settlements in the countryside and the creation of the social, cultural and commercial centres necessary to community life in close proximity to the thoroughfare network. Although Wright's Broadacre City was a completely utopian and impractical social and political project, it was in some respects prophetical, having many of the spatial configurations envisaged in it actually come true, on a large scale in the U.S. and quite extensively also in Europe. Indeed at least in one regard was Wright's proposal very realistic and pragmatic, that is in assuming the centrality of the car in contemporary life. For this reason, the urban reorganization planned by Wright largely came true by itself, as an effect of interactions among individual preferences, market trends, and local planning systems. As Fishman (1990: 37) states:

Wright also had a remarkable insight into the highway-based world that was developing around him. Above all he understood the consequences of a city based on a grid of highways rather than the hub-and-spokes of the older city. Instead of a single privileged center, there would be $a$ multitude of crossings, no one of which could assume priority. And the grid would be boundless by its very nature, capable of unlimited extension in all directions.

Apart from the United States, this out-and-out explosion of the centre envisaged by Wright came true also in European cities, whose commercial, social and cultural centres got dispersed in a multitude of shopping malls, multiplexes, conference centres, sports facilities, entertainment facilities, gas stations, almost always in close proximity to mobility infrastructures. Old historical centres are no more at the top of the urban and regional hierarchy, but are just one of the numerous nodes of a basically non-hierarchical network. A special function was assigned by Wright (1963, 192-193) exactly to gas stations which were supposed to become real community centres dispersed in the region:

One more advance agent of reintegration, an already visible item in the coming decentralization of the City, may be seen in any and every roadside service station happening to be well located along the highways. The roadside service station may be - in embryo - the future city-service-distribution. Each station may well grow into a well-designed convenient neighbourhood distribution centre naturally developing as meeting place, restaurant, restroom, or whatever else will be needed as decentralization processes and integration succeeds. Already, hundreds of thousands occupy the best places in the towns or, more significantly, pretty well outside the towns. Eventually we will have a thousand new city-equivalents at work detracting from every small town or great city we now have. Proper integration of these would help overcome the super-centralization now trying to stand against human freedom.

According to Wheeler (1960, 174), Wright designed for the first time an ideal gas station in the beginning of the 1920s and later incorporated the design in his project for a model community - the Broadacre City. In 1958 Wright himself engaged in the realization of a gas station in Cloquet, Minnesota. Set among the conventional dwellings and small-town business establishments of Cloquet, the gas station had a cantilevered copper roof protecting the filling area and was equipped with large service areas including a restaurant, an observation lounge, and a rest area for travellers. On the top of the roof a lighted 
pylon stood out in the skyline, making of the gas station an urban landmark visible from far away. Each building's detail had been designed by Wright himself. It was complete, among other things, of plant racks and ceramic tiles, and cost more than ordinary gas stations. However, it was conceived for serial production, and scale economies should have lowered its cost per unit.

Also in the case of gas stations, Wright's hypotheses proved to be prophetic and many of these structures are assuming the features of authentic small community centres, for example the already mentioned Autogrill and Ristoragip in Italy.

\section{Autogrill and the Italian Gas Station}

Italy has a peculiar history in terms of gas stations, for two main reasons. The first is related to the partnership formed after World War II by the biggest food companies and the main oil companies, a partnership which led to an early 'implosion' (Ritzer 1999) of the boundaries between restaurants, supermarkets, entertainment facilities, and gas stations. The second reason is the important role played by Enrico Mattei's Eni in building a national energetic policy and in the commitment of Agip - an Eni's controlled petrol company - to create a filling station network also integrating restaurant and bar facilities. The history begins in 1947, with the opening of the first rest station built by Mario Pavesi in close proximity to the Novara exit of the Torino-Milano highway, not too distant from the Pavesini biscuit factory and aimed at its promotion. In 1949 a big arch over the highway was built to mark the station, with a hanging aerostat and the writing Biscottini di Novara Pavesi (Pavesi Novara Cookies). Between 1950 and 1952 the building was expanded realizing an auto-grillroom, a deli-restaurant for motorists. The project was entrusted to the Architect Angelo Bianchetti, who designed a single store building overlooked by a huge concrete arch, with the writing Bar-Autogrill-Restaurant Pavesini Biscuits placed on it together with a greasy pole made of anthropomorphic Pavesinibiscuits and of fluctuating egg. To motorists, then used to eating home-made-sandwiches, a modern and 'American' rest-station was now provided.

With the Novara autogrill starts the adventure of the Pavesi, one of the biggest Italian food industries at that time, in the world of highway restaurants. In 1955 the Bergamo autogrill was opened, and three years later the ones in Lainate and in Ronco Scrivia. The land was owned by Pavesi and the filling stations, which were to be rent to petrol companies, were developed subsequently to the rest area. The entrusted architect is again Angelo Bianchetti, who was awarded the golden award at the ninth Premio nazionale della pubblicità (National Advertisement Prize) for his work on gas-stations. The building is at the same time a commercial totem and a regional landmark. In Lainate and in Ronco Scrivia the fabric has a circular plan overlooked by three big arches converging towards a centre upon which the Pavesi logo is raised up to 5I meters (167 feet). As in the case of Wright's gas station in Cloquet, Minnesota, Bianchetti's project is total, controlling the interior and the exterior of the building, from graphics to signage, from tools to decorations. Such design creates a corporate image, but also symbolising the mass motorization and mobility revolution in Italy, as well as the birth of modern marketing and the advent of mass consumption.

Later on the Pavesi company will make a partnership with the American Esso and will import to Italy the bridge restaurant developed by the Fred Harvey Company, based in 
Chicago. The first autogrill to be realized according to this model was opened in Fiorenzuola d'Arda in 1959. In these new generation of autogrill, restaurants provide menus specifically conceived for motorists under the supervision of the Institute of Physiology of the University of Milan and made of "light, nourishing, healthy and genuine [food], ready at any time, day and night".
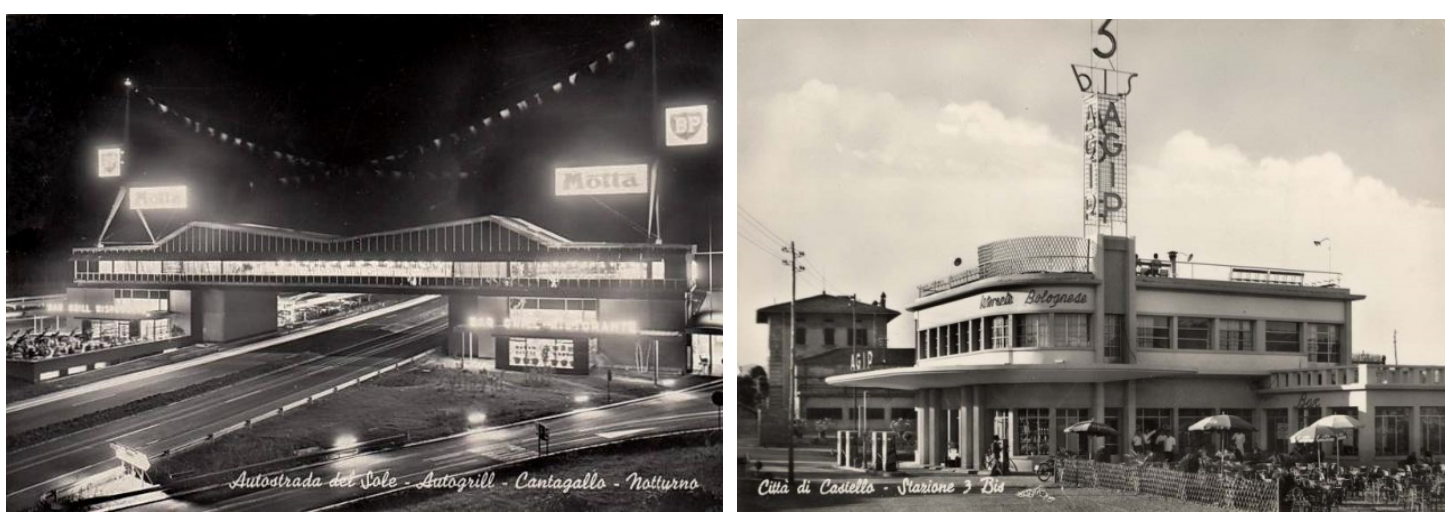

Fig. I. On the left: Cantagallo City. Old postcard (author's collection).

Fig. 2. On the right. Città di Castello. Stazione 3 Bis. Old postcard (author's collection).

The Motta company, a competitor of the Pavesi and the biggest food company in Italy, will enter the competition creating a partnership with the British BP and developing the famous Mottagrill in Cantagallo (BO), the biggest in Europe, also called 'Cantagallo City' (fig. I) The entrusted architect, Melchiorre Bega, interprets the bridge as a huge advertising emblem: glazed walls with big sunscreens, advertising pennons 30 meters high, and a roofing reminding the letter $M$, initial letter of Motta. The complex hosted a restaurant, a book-and-souvenir shop, a branch of the Banca Commerciale Italiana (a major Italian bank), and a branch the of the Ufficio del Turismo of Bologna (the local tourist office). The Mottagrill in Cantagallo becomes in these years a true landmark, also thanks to engagement of the talented cook Marco Bazzani, who raises the profile of the restaurant to nationwide reputation. 'Andare al Cantagallo' ('going to Cantagallo') was in great fashion also among famous personalities, including Frank Sinatra, Brigitte Bardot, Gregory Peck, so to seriously compete against the most famous restaurants of Bologna (Variante di valico, 2013).

From the beginning of the 1950s, also Enrico Mattei's Agip invested several resources in the commercial network, which was in charge of conveying the corporate image of the company: architectural models were developed, large investments in station-managers' training were made, corporate periodicals were created such as "Buon lavoro, Amici!" and "Il Gatto Selvatico". In one of these magazines it was possible to read in 1956: "Rests in the middle of nowhere no more exist. Beside filling stations arouse bright rooms, equipped with the most modern facilities, real residences, open 24 hours a day, in all climates. They are agile and slim structures, they make you think to a happy season, to trades getting crowded with new signs, with new homes for people" (Parrella, I956). To the Pavesi's American style, Mattei opposed a local prototype based on a new national identity. After the advent of the autogrill also Agip entered the Market forming a partnership with Alemagna, a competitor of Motta and Pavesi. The result of this 
partnership were the autobar, whose sobriety was shown by the absence of table service. These were mainly prefabricated buildings assembled at the Nuovo Pignone, a company taken over by Eni in 1954, and hosting in a single block both the bar and petrol pumps. The simplicity of Agip gas stations makes you think to a catholic Eni, devoid of the typically American redundancies: they display a sort of ideological aesthetics flattering national self-regard.

The cultural importance of autogrill should be understood within the tremendous transformations undergone by Italian society in the post Second World War era. The 1950s are the years of the economy car, television, and the advent of mass consumption. In 1954 Fiat launches the Seicento, and the year after 126.000 models are registered, despite its price being equivalent to a one year blue-collar wage. The economy car transforms free time and is a symbol of liberty and escapism. In 1954 also start in Italy TV broadcasting and its widely enjoyed Caroselli, the famous advertising shorts interpreted by the best actors of that time. The first Carosello to go on air will be the advertisement of an oil company, Shell, although all the main protagonists of highway rest will be largely screened: from the "healthy, light and nourishing Pavesini ("Pavesini: sani, leggeri e nutrienti”), to Alemagna's greasy poles.

In these years autogrill consolidates as one of the major symbols of the so-called 'Italian economic miracle' and of the new bourgeois consumption. Its symbolic importance is demonstrated by many opening ceremonies, which are attended by the highest political and religious authorities. The opening ceremony of the Cantagallo Mottagrill, on April 29 ${ }^{\text {th }}$ 1961, for example, was attended by the undersecretary of Ministry of Education Elkan, and by the Archbishop of Bologna Lercaro, who even compared it to a small rest stop existing in Galilee in the time of Jesus. Even the journal Life International, in its September $26^{\text {th }} 1960$ edition, reported on the autogrill phenomenon:
Nowhere in Europe is the new prosperity more spectacularly evident, afloat and ashore, than in Italy. [...] Now Italy produces luxuries for home consumption and imports them as well. In Milan [...] alone, 350,000 citizens have passports; 10 milion radio sets and 1.6 milion television sets help Italians spend their leisure time when they are not at the theater, the movies or a football game. Usually they ride to their entertainment, often pausing to enjoy the allurements of an «autogrill», or roadside restaurant. The establishment brightening the night (above), one of I 3 in Italy, offers lunch or dinner for $\$ 1.20$, a bar and a wide variety of objects for sale including «exclusive» american bags (below) at a little more than $\$ 2$ each. The Pavesi Biscuit \& Cookie Co., which operates the grills, stuffs the pocketbooks, picnic baskets and beach bags that it displays with Pavesi products, some of them imported, others homemade, but all of them silently eloquent reminders of Italy's new standards of life and living.

Although the first autogrills took inspiration from some Northern-American examples, the happy alliance between food industry and oil industry is a typically Italian phenomenon which has no equivalent for its dimension in any other country in the world. The biggest highway-restaurant market in Europe is still the Italian one, and Autogrill SpA, the key player emerged after a long merging and restructuring process in the sector, is nowadays a global player producing $70 \%$ of its sales abroad with over 4.800 branches and 51.000 employees.

Thanks to the success of this experience - initially developed only in close proximity to the highway network in order to make it autonomous from inhabited areas - the union 
between gas distribution and food services became a widespread phenomenon in Italy, from the small filling station in the country in partnership with the coffee and pastry shop, to the station with annexed bar/restaurant in the urban peripheries, to the one with annexed pizzeria and small supermarket in medium-distance roads (fig. 2). Thanks to prolonged opening hours and to excellent accessibility, this secondary distributive network is becoming an important social infrastructure. In order to understand this network, gas station cannot be interpreted following the bleak visions of 'non-places', a structured research on uses and actors of these only apparently unusual small community centres is needed to unpack their true nature.

\section{The Social Life of Italian Gas Stations}

Our empirical analysis focused on two gas-stations in the South-west periphery of Florence, both owned by TotalErg, an oil company borne in 2010 after the merging of the French Total-Italia and the Italian Erg Petroli. They have been selected through a survey of gas stations in the Florence Area; selection of case studies was based on mixture of functions, accessibility, opening time, as well as likelihood of becoming spaces for social interaction.

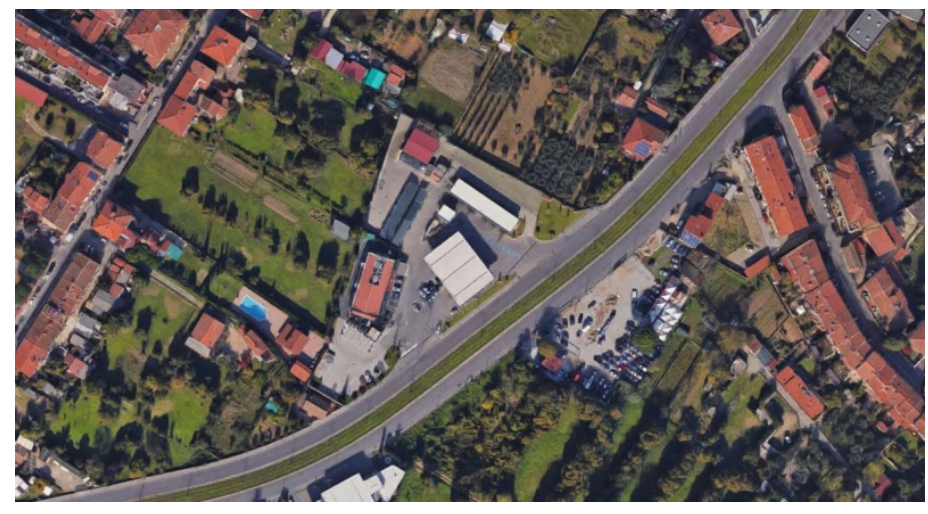

Fig. 3. Google Maps.

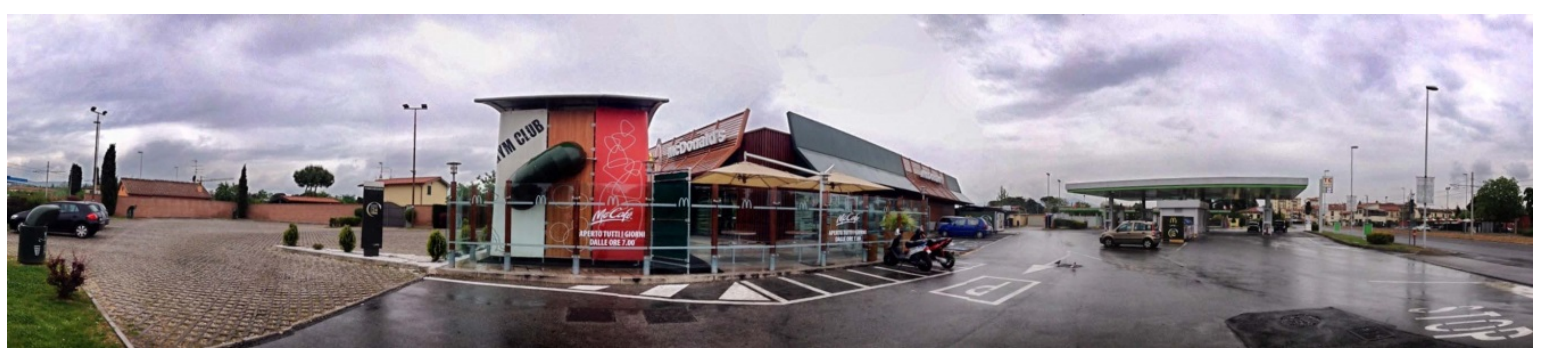

Fig. 4. Photo: Giulio Giovannoni

In the selected area, there are different types of gas stations, from small installations in the compact city with I-2 pumps to medium size stations with bar and restaurant, mainly located in the suburbs, to large Autogrills on highways. The two medium-size suburban gas stations selected for our research are both with bar/restaurant open 24/7. From a social point of view this is probably the most interesting type as it intercepts a local population in an area with scarce public places. 
The first station is located on the Viale Nenni, a four-lane-urban road lined by the Firenze-Scandicci tramway, constituting the main axis connecting Florence to Scandicci, a big residential neighbourhood South-West of Florence with a population of about 60.000 inhabitants. This gas station is also equipped with a large car-wash service, a parking lot, a MacDonald's and a McDrive, the latter two open until II p.m. on weekdays, 24 hours on weekends. In reporting the results of the analysis I will indicate this case study as the McDrive Gas Station (MDGS) (fig. 3-4).

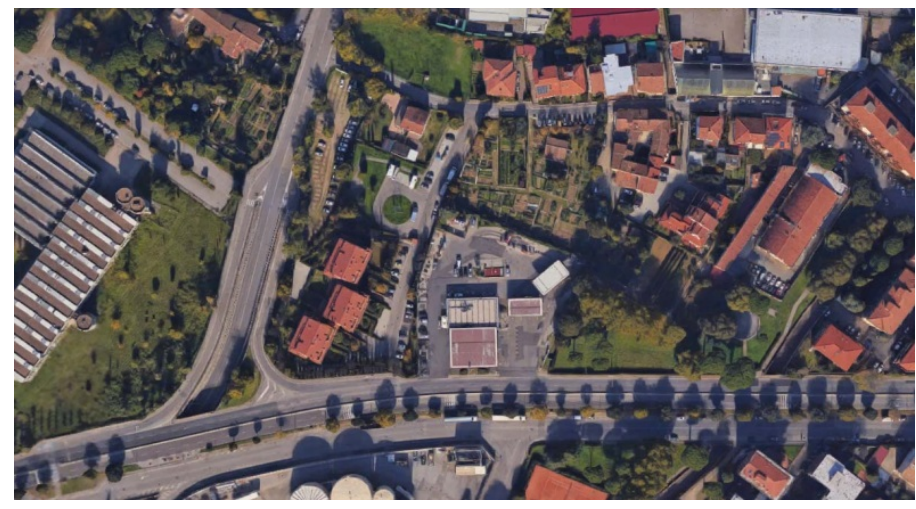

Fig. 5. Google Maps.

The second case is located on a four-lane-urban road that feeds into the Firenze-PisaLivorno highway. The gas station is equipped with filling facilities, coffee-pastry shop open 24/7 with also newspapers sale, parking lot, car-repair service, car-wash service, and natural gas station. In reporting the results of the analysis I will indicate this case study as the Pastry Shop Gas Station (PSGS) (fig. 5).

\section{I. Research Methods and Goals}

This section describes the research questions and aims of the empirical study carried out on the two gas stations and explains the methods used to answering such questions. The analysis used a range of tools, from long term observation to interviews to mapping techniques. The research was designed to include the following aspects:

- social life of the gas station in different times of the day and of the week;

- spatial and social relationship between the gas station and its neighbourhood;

- relationships and synergies between the various activities hosted by the gas station;

- city 'à la carte' and urban routines;

- gas station's publicness.

Social life of the gas station in different times of the day and of the week. In order to understand and to describe the social life of the gas stations we investigated the following questions (cfr. Gehl \& Savarre 2007):

- How many people and what kind of people (by age, gender, ethnicity) are there in each sub-unit of the gas station in different times of the day and of the week?

- What are they doing?

- For how long? 
This in vivo study of public space has found a growing legitimacy in the theoretical debate on territoriality in recent years. This view was fostered, among others, by Sack (1986 p. 19), who defined territoriality as the "attempt by any individual or social group to affect, influence, and control people, phenomena and relationships by delimiting and asserting control over a geographical area". On this topic see also Brighenti (2010). The notion of territory understood as a bounded and controlled space has been questioned by highlighting the fluid and changing nature of territorial appropriations (e.g. Delaney 2005, Brighenti, 20I0; Kärrholm, 20I6). It became clear that territories, conceived as socially produced spaces, continuously change both their shape and content. In our case, the gas station and its sub-units are lived by different publics in different times. Therefore, understanding the social life of a gas station means describing how its publics and their performances change in space (sub-units) and in time (daytime, weekdays). We used structured observation methods (Gehl \& Savarre, 2007; Gillham, 2008) to understand such variations. In order to count users and to register their activities, we adopted a 'time sampling' technique with a time period of ten minutes. By 'time sampling' we mean observation at regular intervals for short periods of time (Gillham, 2008: 14-18); this approach makes the different measurements comparable. During the observation pedestrian movements were also mapped. This quantitative measurement was integrated with more properly ethnographic work, which consisted in participatory observations within the gas station. Short unstructured conversations were held with managers and with other customers. We kept these conversations as the most spontaneous as possible, while trying to direct them towards the areas of interest for the research.

Structured observations were carried out in April 2014. We first checked the place out in different moments of the day, observing differences in the use of gas stations in the morning, afternoon, and evening. We then developed an observation sheet which covered the different moments of the day in both working days and weekends. Altogether, 24 hours of observation were conducted in each petrol station, for a total of 48 hours. The stations were divided into sub-units, which were observed separately.

Spatial and social relationship between the gas station and its neighbourhood. Gas stations we surveyed are architectures on the road located in an urbanized environment; being on the road they are designed to be reached by car; belonging to an urban environment, although fragmented and suburban, they lend themselves to be used as neighbourhood facilities. One of our goals was investigating to what extent the gas stations are used by local residents. To accomplish this, we first observed the number of users who reach the gas station on foot. We also tried to establish if there was a significant percentage of users driving to the gas station and living nearby or going there on a regular basis. While the number of people going on foot to the station can be easily determined through observation, establishing how many motorists live in the neighbourhood requires more in depth investigations, which were outside the initial scope of this research. Partial data about provenience of users were acquired through unstructured interviews with gas stations attendants, who have some general knowledge of their regular customers.

Relationships and synergies between the various activities hosted by the gas station. The gas stations host several activities that can work independently of each other; for example, there may be people who go to the gas station only for petrol, and people who go to the 
gas station only for the bar or for the McDonalds. However, there may be people who simultaneously use more than one of the services offered by the station: for example they fill up, they wash the car, and then they go to the bar or to McDonalds to have a good time. This 'complex' usage of the gas station can be done individually or in group. In the case of a family, just to make an example, the father can fill up and wash the car, while the mother and the children wait for him at the McDonalds. It is important to evaluate these interactions/synergies as they are one of the features of public spaces. The evaluation was done through direct observation by estimating the percentage of people, or groups of people, simultaneously using two or more of the services offered by the station.

City 'à la carte' and urban routines. The contemporary city is featured by a widespread and pervasive use of the car. Robert Fishman (1990) effectively defined it 'city à la carte'. In fact, thanks to the freedom of movement made possible by the car, people decide their routes and their stops in the same way in which they order their food at the restaurant. That being the case the stop at the gas station is normally just one of the stops along a more articulate individual (or group) journey. Urban sociologists (e.g. Cohen \& Taylor, 1992) use the term 'urban routine' to indicate those systems of moves/stops that become a regular occurrence in the daily lives of people. During the anthropological phase of the fieldwork we investigated the urban routines of gas stations' users.

Gas station's publicness. In terms of ownership gas stations are obviously private spaces. However, they offer public services and raise no particular access restrictions. So the problem of how evaluating their publicness is being raised, which is far from trivial. The traditional dichotomous distinction between public space and private space is simplistic and largely outdated. Kohn (2004) argues that there are several hybrid forms of public/private spaces and that the "progressive blurring of the boundaries makes it necessary to develop a flexible definition of public space.” Marcuse (2004: I I3, note 32') identifies six legal forms of space which depend on the public/private nature of three distinct variables: ownership, function, and use. Petrol stations equipped with coffee shops/restaurants open 24/7 clearly fall into Marcuse's category 'private ownership/private function/public use'. Shopping malls as well as many other private facilities also belong to this category. However, whereas literature on shopping malls is quite extensive (e.g. Parlette Cowen, 20I I; Staeheli and Mitchell, 2006; Miller et al., 1998; Backes 199; Crawford, 1992), given their relevance in the urban structure and in everyday life, petrol stations have never been studied as socially relevant artefacts.

But the problem is more general; research trying to define and to measure urban-spacepublicness is very scarce and applies to situations that are quite different from the context of our research. Van Melik et al. (2007) developed a model to measure publicness which is visually represented by a cobweb diagram. It is designed for themed/secured urban spaces and has six rays, each corresponding to a 'dimension' of publicness, and three concentric circles, each corresponding to a measurement level (high, medium, low); Three of the six rays/dimensions are dedicated to secured public spaces (surveillance, restraints/loitering and regulation), and three to themed public places (events, fun shopping, pavement cafés). Giving a high/average/low score each to each axis/ray cobweb figures are produced that graphically show the degrees of securedness and themedness. Németh and Schmidt (20II) developed a model in which publicness is defined and 
measured in relation to three axes: ownership, management, and uses/users. Both aforementioned models are deficient, since they do not take into account the design and the localization of the spaces which they intend to assess. This bias is particularly relevant to our case. In fact, as we demonstrated in the historical section of this paper, the social significance of contemporary hybrid public/private spaces, such as gas stations and shopping malls, is largely determined by their location on the road and highway network or in close proximity to it. Although designed for the measurement of publicness in urban waterfront environments -that is in spaces that are quite different from ours- the star model conceived by Varna and Tiesdell (2010) is better suited to our purpose and adopts criteria which appear to us overall more balanced. In fact, compared with the aforementioned models developed by Van Melik et al. $(2007)$ and by Németh and Schmidt (20II), it introduces parameters which measure centrality, access, and possibilities for active and passive engagement with the site.

Importantly, all measurement models of publicness found in literature, including that of Varna and Tiesdell (2010), which we actually used, are inductive models which study public space as something external to people. The assessment is done by the researcher and is based on the attribution of a value to each of the valuation parameters. Since this process is largely subjective, we tried to give adequate reasons for the values that we assigned. However, we argue that this bias is also offset by having used a number of complementary research methodologies (historical framing, structured observation, ethnographic observation).

\subsection{Research findings}

Social life of the gas stations in different times of the day and of the week. The structured observation of the two gas stations clearly shows that their social life and their publics deeply change across time, both during the day and during different days of the week (working days/weekends). So we can talk of multiple productions of space, which change both in space (parts of the gas station being lived) and in time. At the MDGS mornings are quite calm on weekdays, but quite crowded on weekends. People's activities, however, are mostly confined to car maintenance and social interactions are scarce. Lunchtime instead seems to be one of the most socially interesting periods in any day of the week. People appear to be very mixed in terms of group-size (from large groups arriving in several cars, to families, to individual users), of ethnic backgrounds, and of social classes (evaluated on the basis of the kind of vehicle driven). The late afternoon is markedly different from the lunch hours. Traffic diminishes, and a different type of user appears. On Saturday afternoon, we observed several groups of at least 4 teenagers arriving on foot, plus another middle aged man. The clients were generally young, from 16 to 20 years old, and there were few families. The early part of the evening is one of the busiest times, with the McDonalds filling up around 6.30 and the car wash in full function until dark. In general, the dinnertime atmosphere around the restaurant is different from lunchtime, as there are fewer families and elderly, but more young people and middle aged without children. In the evening the McDonalds becomes a meeting point for local teenagers. We observed many that did not enter inside, but used the parking as a meeting place. There were also older people using the parking lot as a social area. For example, some 30-yearold males were gathered around the modified car of another, examining it and eating their hamburgers. 
Analogous space-time variations of social life were registered at the PSGS. This is particularly active during night-time, especially on weekends. The pastry shop is a true landmark for younger people. On weekends it is largely used as a place both to start the night (before going to disco, to the movie theatre or to amusement centres) and to end the night (e.g. having pastry after disco in the early morning). Even on a Monday night many young people, up to 40 years old, were observed standing in front of the pastry shop, drinking, and talking relaxed. Reviews posted by gas station's customers on social networks, confirm its relevance for this kind of public. After all, as one of its night customers argued, the TE Pastry Shop is "the only place open at night in the Isolotto neighbourhood". Compared to the MDGS however the PSGS appears to be more physically disconnected from the neighbourhood and no single person was observed walking to it.

Spatial and social relationship between the gas station and its neighbourhood. Going even beyond our expectations, both gas stations resulted having a relatively strong social connection to their surroundings. Most of the McDonalds clients are local, and come there often. This was clearly stated by an attendant who said: "most of the clients are from the neighbourhood, we know many of them by name - there are few tourists here". Although they come mostly by car, as coming on foot is not very convenient, we were surprised observing several groups of teenagers walking here from the neighbourhood on a Saturday afternoon. The station is in fact located in a very dispersed area, and there are only few inhabitants in the space of at least two hundred meters. In the case of the PSGS we should distinguish between its spatial relationship and its social relationship to the neighbourhood. The station is in fact quite physically disconnected from the neighbourhood, being located on a thoroughfare on one of its edges, and being almost impossible to get access to it on foot. However, its social relationship to the neighbourhood appears to be strong, especially for younger people. Also, as one of its night users observed the gas station is "the only place open at night in all the Isolotto neighbourhood".

Relationships and synergies between the various activities hosted by the gas station. As we started our empirical analysis we expected to find strong synergies between food and gas. Instead we found that both in the MDGS and in the PSGS people using the gas station for car-related activities tend to be distinct from people using it for food-related activities. Only a small number of users take advantage of both functions. These findings surprised us and are in a sense counter-intuitive. However, a deeper analysis reveals that strong synergies between food and gas still exist. For example, although at the PSGS most of the pastry shop customers don't refill their car, they take great advantage of the oil company's parking areas and cantilever. Its location under the cantilever makes the pastry shop enormously more usable: it is always safe and lighted, always covered from rain, always easy to park. This explains why the gas station filling cantilever tends to become in certain moments an outer extension of the venue. Also the pastry shop gains a lot in terms of visibility, especially at night, thanks to the oil company's visual signs. At the MDGS the situation is quite different. The McDonalds in fact tends to be an enclave: it has its own outer space equipped with tables, but this is accessible only from the inside of the venue. However, in the MDGS some outer social spaces are spontaneously created as 
well, independently from the McDonalds. The most evident is the scooter parking area in front of McDonalds, which transforms into a meeting place for teens, who then stay there, blocking foot and car traffic. At various times, different areas of the parking lot are also used for social activities, particularly in the evening (fig. 6-7).

City 'à la carte' and urban routines. The gas stations evidently play a different role in people's routines on weekdays and on weekends. On weekdays at the MDGS we saw many small groups of people who were obviously taking their lunch break there. The most conspicuous was a group of about 25 firefighters, all dressed in fluorescent orange, and making a lot of noise. Interestingly individual users were almost absent. On weekends the picture is much richer.
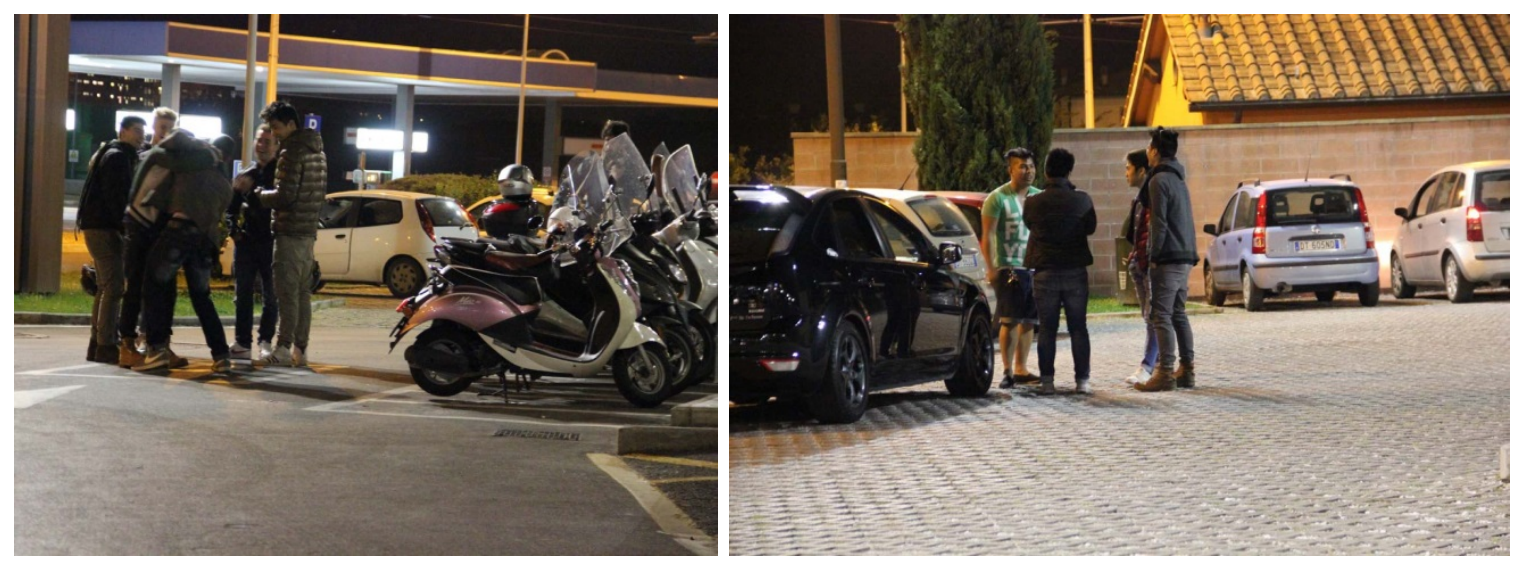

Fig. 6-7. Photos: Giulio Giovannoni.
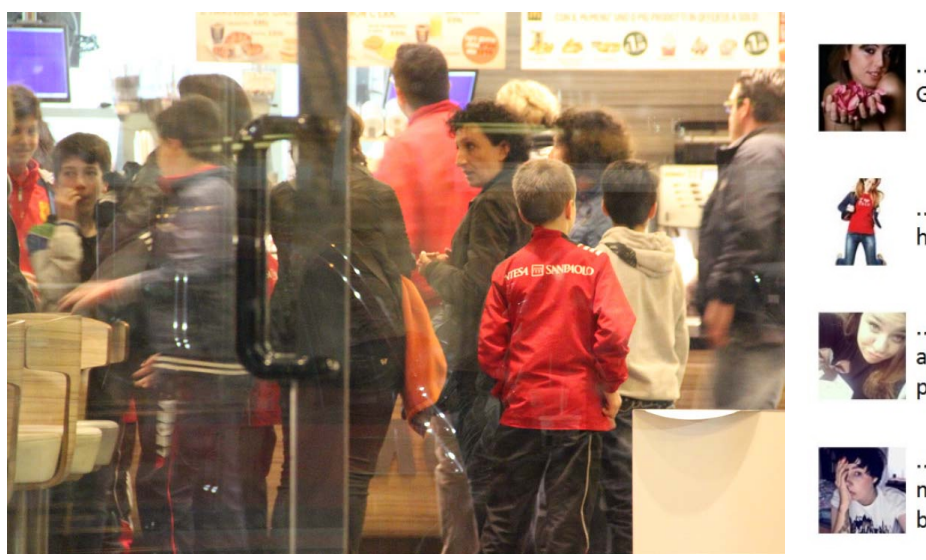

...this place is a hoot for night Gourmands!

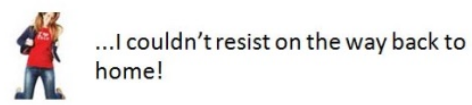

Fig. 8-9. Photos: Giulio Giovannoni.

On the right: comments of some young users of the PSGS on Yelp! http://www.yelp.com/biz/pasticceria-ergfirenze, accessed on April II, 2013.

In the late afternoon we noticed many parents coming with their children, mostly male, after football or other sporting activities. At night, a worker told us, many people that stop there are on their way out for other destinations. Our observations of clothes and other signs confirmed this. The employee also said that after the clubs close, many people pass through the drive through on their way home. We saw two women, aged 30 , 
obviously dressed to go out, arrive at about I0pm, on their way into Florence. We spoke with a 17-year-old from Calenzano, who had been waiting there for at least 30 minutes before his friends arrived. When they arrived, the group remained outside, saying that they had no intention to go to McDonalds, but would go somewhere else. So, the parking lot area is both a social space for them, as well as a departure point for whatever other activities they would be doing that evening. The situation is not too different at the PSGS, which is also much used by youngsters during their nightlife routines, especially on weekends (fig. 9).

Publicness. The variety of uses visible at the gas stations can lead one to conclude that the exterior spaces here are essentially public spaces in terms of active control. There is nobody there to stop you from doing whatever you want. The space is accessible to all, and used by a wide range of people. The constant presence of others and the tight, awkward spaces almost police themselves. Still, there are no rules to which you must conform, other than the general ones that govern you in any place. We could say that these gas stations, and particularly the areas around McDonalds and the pastry shop, are automatically policed by the large amounts of users that pass through. In that sense, they are very public - the large amount of users at key times is typical of an urban public space. But differently from other more traditional urban spaces which have an almost continuous presence of people, social life at the two gas stations lights up especially at certain times: at lunchtime, in the afternoon, and at night, particularly on weekends. Some of the other areas are less frequented, and hidden by buildings, but we observed no illicit users taking advantage of the privacy.

In order to make our analysis more specific and to provide a measurement of publicness we applied Varna and Tiesdell's (2010) model. This model consists of five dimensions whose values range from one (low publicness) to five (high publicness). The lowest score, according to this model, is five (lowest score in all variables), and the highest one is twenty-five (highest score in all variables). The first variable to be considered is ownership. The model attributes three points to situations like ours. The criterion is: 5 points in case of public ownership; 3 points in case of public/private partnership, transit interchange, retail premise; I point in case of private ownership. The second variable is control. The two opposites considered by the model are the 'big father' situation, protecting the freedoms and liberties of citizens (five points), and the 'big brother' situation, protecting the interests of the powerful (one point). The first is featured by no visible/overt control, no CCTV cameras evident, regulations enacted only in the interests of the community. The second is characterized by highly visible expressions of control presence (especially security guards), many CCTV cameras evident, regulations enacted in a narrower private interest. In our gas stations we have no visible/overt control, no particular regulations enacted in the private interest (such as in many shopping malls), and just a few scarcely visible CCTV cameras. Therefore, we give four points to this parameter. The third variable is civility. In this case a high level of publicness depends on the space being well kept and cared for, and on being provided of basic facilities such as toilets, shelters, food vendors, seats, and lighting. As we already discussed, in the PSGS the space in front of the pastry shop is very well equipped: it is sheltered, it has toilets, it has food, it has some seats available on the outside, and it is very well lighted (fig. 10). 


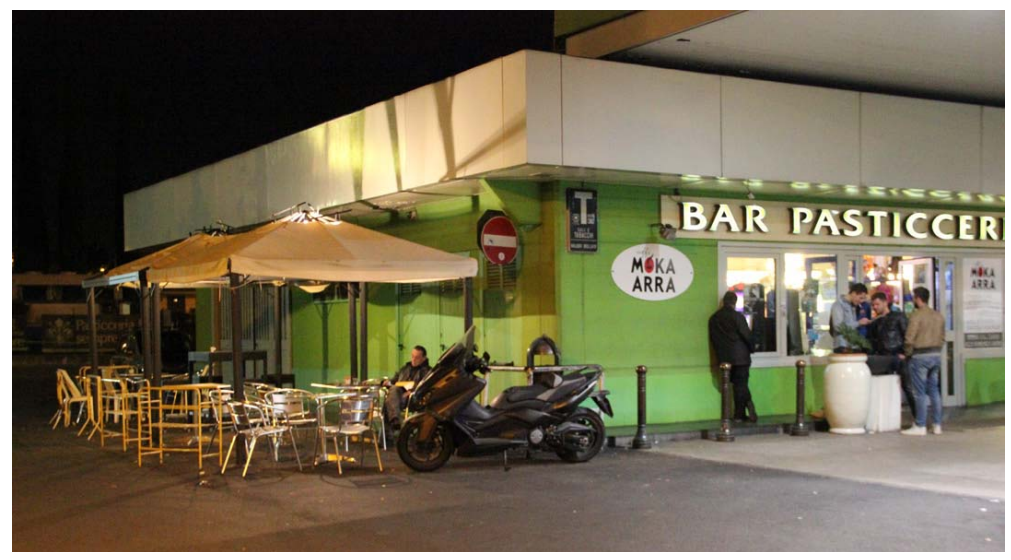

Fig. 10. Photo: Giulio Giovannoni.

The area in front of McDonalds in the MDGS is also well equipped but is more enclaved and therefore less public. Both gas stations are also very well kept and maintained. We give five points to the PSGS and four points to the MDGS. The fourth variable is physical configuration. A high score is determined by centrality/connectedness, by visual permeability, and by the absence of thresholds and gateways. Centrality is defined in terms of good location 'within the overall movement network', whereas being visually permeable means having 'strong visual connections with external (surrounding) public realm'. Both gas stations are highly central within the overall movement network, have strong visual connection with the surroundings, and have no thresholds or gateways limiting access to them. We could argue that these facilities are punctual and isolated, but in our mind this only holds true only if you are a pedestrian, not if you act as a driver, as most of their users do. We give five points to the variable 'physical configuration'. The fifth and last variable is animation, measured in terms of opportunities for active and passive engagement, and of opportunities for discovery and display. According to the model, opportunities for passive engagement are determined by reasons for peoplewatching, and by multiple and varied formal and informal seating. Opportunities for active engagement are considered to be provided if there is high density of active frontages, and diversity of events and activities occurring spontaneously or through programming. Finally, opportunities for discovery and display are provided by loose, adaptable spaces, which can be used in multiple ways. On this variable our gas stations are weak. There are no particular events being held there, apart from the aperitif events organized at the pastry shop, the density of active frontages is not high, and there are not too many seating opportunities. Also space is not particularly adaptable: we ever observed people playing football or doing similar things. However, gas stations offer interesting opportunities for people-watching, there being continuous flows of users of any kind. We cautiously give one point to this variable. Finally, the MDGS scores 17 points, and the PSGS scores 18 points out of 25 in terms of publicness. With all the limits already highlighted in the methodological section ( $(4.1)$ the application of Varna and Tiesdell's (2010) model is quite useful in determining gas stations' strengths and weaknesses. The strengths of the two gas stations which we investigated are that they offer important facilities (food, toilets, light, shelters, and places to sit), that they are safe and controlled, well maintained, highly visible and accessible, they pose no particular 
restrictions to what people can do. Their weakness is that they pose no sufficient incentives to doing a range of different activities.

\section{Conclusions}

In this paper I tried to demonstrate that gas stations are central spaces in contemporary cities. The topic has been approached reviewing the main positions on gas stations, from the pessimistic views which equate them to nonplaces, to the enthusiastic ones which glorify their value in relation to street cultures.

Then I started examining the main causes which make gas stations important. These causes are mainly related to transformations induced by the car on cities, and hold equally good in all countries. Such transformations led F.L. Wright to the visionary proposal for a gas station conceived as a dispersed community center within the Broadacre City. Beyond these causes there are historical and economic reasons that make the social function of gas stations generally more important in Italy than in other countries. These reasons, examined in the paper's third section, are related to the partnership formed after WWII by food industry and oil industry. This partnership started with autogrill in close relationship to the highway network. Later on - thanks to the smaller and more dispersed stations realized first by Agip and then by all the other oil industries - the marriage food + gasoline had a widespread diffusion. The 'implosion' of the gas station into the restaurant/coffee shop together with its high accessibility made of the gas station the place of numerous social interactions.

After having supported the hypothesis of the centrality of gas stations within social contemporary life through historical analysis, I started checking it through fieldwork. Two gas stations in the periphery of Florence were chosen which looked promising, and various analytical and observational tools were applied to them. In both cases the initial hypothesis was confirmed. Both the gas station with annexed a McDonalds and the one with annexed a pastry shop are true social landmark for the inhabitants of the area. Their function goes well beyond the temporary and transient stop, contributing these places to their neighborhoods' identities and being at the core of stable and continuing interactions, especially for younger generations. Of course we can't expect gas stations to be the equivalent pedestrian squares located in the historic city center. Their social live is not as continuous, being intense only in particular times of the day and of the week.

Nevertheless, four out of five of the criteria established by Varna and Tiesdell's model are largely satisfied, and this explains why gas stations are socially active. The application of that model also highlights their main weakness, which comes from the limitedness of the range of activities that can be done over there. However, in a city which is more and more complex and diverse, gas stations can play an important role and this role should be clearly recognized by planners, by designers and by politicians. The policy implications of this analysis are clear and important. It's necessary to go beyond the dominant idea that gas stations necessarily are alienating spaces, or at best just technical artefacts. They are complex structures and as such they need to be designed thinking to the important social function which they detain in contemporary society and life. If we understand the potential of gas stations they can sure become, more than they already are, great places for public life and positively contribute to the provision of services in suburban areas. 
But the implications of our research go far beyond that. Rethinking gas stations is part of a wider process of rethinking public life and public spaces in contemporary human settlements. Although cities underwent radical transformations in the last century, our way of looking at urban life is still closely related to traditional public spaces such as squares and streets. We provide a background and conceptual positioning for the argument of gas stations as public spaces, and a method for their empirical investigation. These can usefully be applied to the study of other spaces which also play an important role in contemporary life but which have been scarcely investigated so far. We argue that developing new research in this direction is vital for overcoming still dominant urban paradigms and for creating the cultural and cognitive conditions for more finely tuned governance of contemporary human settlements.

\section{Acknowledgements}

A conversation held with Marco Cenzatti, at University of California Berkeley in Spring 2013 helped me understanding the relationship between autogrill and contemporary gas stations in Italy. The case study analysis takes advantage of empirical investigations done by students of the course "Rethinking Nonplaces", at the Department of Architecture, A.Y. 20I3-I4, under the guidance of me and of Prof. Paolo Costa. Particular thanks to two anonymous reviewers for their valuable comments.

\section{Note}

(I) «One might thus conceive of six legal forms of ownership of public space. Here I provide a typical example of each of the six legal forms of ownership of public space:

- Public ownership, public function, public use (streets);

- Public ownership, public function, administrative use (city halls);

- Public ownership, private function, private use (space leased to commercial establishments);

- Private ownership, public function, public use (airports, gated communities, zoning bonus private plazas, community benefit facilities);

- Private ownership, private function, public use (cafes, places of public accommodations); and

- Private ownership, private use (homes)»

\section{References}

Augé, M. (1995). Non-Places. Introduction to an Anthropology of Supermodernity. London: Verso.

Backes, N. (1997). "Reading the Shopping Mall City". In The Journal of Popular Culture 3I(3), pp. I17.

Bohigas, O. (1986). Reconstrucción de Barcelona. Barcelona: MOPU.

Brighenti, A. M. (2010). "On territorology, towards a general science of territory". In Theory, Culture and Society (27), pp. 52-72.

Brinckerhoff Jackson, J. (1997). Landscape in Sight: Looking at America. New Haven: Yale University Press.

Cohen, L. and Taylor, L (1992). Escape Attempts. The Theory and Practice of Resistance to Everyday Life. 2nd ed. London: Routeledge.

Crawford, M. (1992) "The World in a Shopping Mall". In Sorkin, M. ed. Variations on a Theme Park: The New American City and the End of Public Space. New York: Hill\&Wang, pp. 3-30.

Delaney, D. (2005). Territory. Oxford: Blackwell. 
Desideri, P. (1995). Città di latta. Favelas di lusso, autogrill, svincoli stradali e antenne paraboliche. Milano: Costa\&Nolan.

Eran, B.J. (20I2). Rethinking a Lot. The Design and Culture of Parking. Cambridge (MA): The MIT Press.

Fishman, R. (1990) “Megalopolis Unbound”. In The Wilson Quarterly I4 (I): pp. 24-45.

Gehl, J., and Svarre, B. (20I3). How to study public life. Washington, DC: Island Press.

Gillham, B. (2008). Observation Techniques: Structured to Unstructured. London: Continuum.

Ingersoll, R. (2006). Sprawltown. Looking for the City on its Edges. New York: Princeton Architectural Press.

Life International (1960). "Italian Luxury for Export and for Those at Home, too". 26 Sept., p. 17.

Kärrholm, M (2016). "The temporality of territorial production - the case of Stortorget, Malmö". In Social \& Cultural Geography, forthcoming.

Kohn, M. (2004). Brave New Neighborhoods. The Privatization of Public Space. London: Routledge.

Kunstler, J.H. (1994). The Geography of Nowhere. New York: Touchstone.

Marcuse, P. (2004). "The 'threat of terrorism' and the right to the city". In Fordham Urban Law Journal 32(4), PP. I0I-II9.

Miller, D., et al. (1998). Shopping, Place and Identity. London: Routledge.

Németh, J., and Schmidt, S. (20II). "The privatization of public space: modeling and measuring publicness". In Environment \& Planning: Planning \& Design 38, pp. 5-23.

Parlette, V., and Cowen, D. (20II). "Dead Malls: Suburban Activism, Local Spaces, Global Logistics". In International Journal of Urban and Regional Research 35(4), pp. 794-8I I.

Parrella, M. (1956). "Stazioni di servizio crocevia della vita moderna". In II Gatto Selvatico II(6), pp. I2-I3.

Ritzer, G. (1999). Enchanting a Disenchanted World: Revolutionizing the Means of Consumption. Thousand Oaks, London, New Delhi: Pine Forge Press.

Sack, R.D. (1986). Human Territoriality: Its Theory and History. Cambridge: Cambridge University Press.

Staeheli, L. A., and Mitchell, D. (2006). "USA's Destiny? Regulating Space and Creating Community in American Shopping Malls." In Urban Studies 43(5/6), pp. 977-992.

Van Melik, R., Van Aalst, I., and Van Weesep, J. (2007). "Fear and fantasy in the public domain: the development of secured and themed urban space". In Journal of Urban Design I2(I), Pp. 25-42.

Variante di Valico (20/3). "A Cantagallo lo chef da Oscar". 8(2), p. 6. Available at: https://www.autostrade.it/documents/10279/4150I/newsletter-33.pdf. Accessed 10 August 2016.

Varna, G. and Tiesdell, S. (2010). "Assessing the Publicness of Public Space: The Star Model of Publicness". In Journal of Urban Design I5(4), pp. 575-598.

Wheeler, R.C. (1960). "Frank Lloyd Wright Filling Station, 1958". In Journal of the Society of Architectural Historians 19(4), pp. 174- 175.

Wright, F.L. (1963). The future of architecture. New York: Horizon Press. 